\title{
Michael Fletcher
}

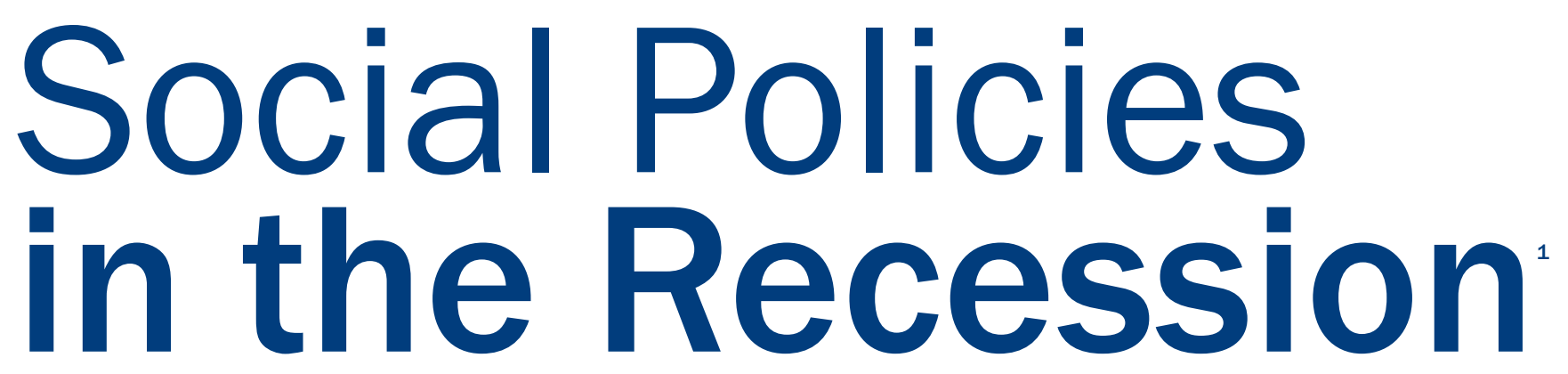

\section{Introduction}

While we cannot prevent many of the current recession's impacts, there are real social policy choices open to policy makers choices that can reduce its severity, influence who bears what costs, and, importantly, have an impact on the longer-term, postrecession outcomes. How well New Zealand performs economically and socially in the years after the current recession is over will depend in part on how well we manage the distributional consequences of the recession and on the social policies implemented during the recession.

Michael Fletcher is an independent public policy analyst and economic researcher. He worked for ten years in the labour market policy group of the Department of Labour on employment policy and immigration issues. More recently he has worked in the Ministry of Social Development on child poverty issues and the Working for Families reforms and as Group Manager, Policy and Research for the Families Commission. He is co-author of $A$ Fair Go for All Children: actions to address child poverty in New Zealand, published by the Children's Commissioner and Barnardos in August 2008.
In the last significant downturn, from 1988 to $1993,{ }^{2}$ New Zealand did poorly in terms of social policies and social outcomes. The result was that on some indicators, for some groups and in some communities the consequences of that recession lasted well into this decade. Associated with this has been an economic cost in terms of higher social expenditures and lower productivity. It may be that the current recession will not be as prolonged or as severe as that of the late 1980s-early 1990s, but it is looking increasingly likely that it will be. At the time of writing the Reserve Bank is forecasting unemployment to peak at about $6 \%$; other commentators are suggesting that the figure could be nearly $9 \%$ and many are talking of a long, 'L-shaped' recession with a slow recovery.

In this paper I review a number of key social indicators as a way of assessing our social 'starting point' in comparison to the late 1980s. I then suggest some priorities and principles for social policies through the recession, before very briefly commenting on three key policy areas.

\section{Where are we starting from?}

\section{Employment and unemployment}

The employment rate - the percentage of the working age population that is in work - is currently higher than at any point since the Household Labour Force Survey began in 1986 (see Table 1). There are, however, significant differences between sub-groups of the population. In particular, the long trend towards convergence between male and female employment rates means that the female employment rate, at $60.1 \%$, is now significantly higher than in 1987 , while the male rate, although it has risen in the last five years, remains lower than before the last recession.

In terms of ethnicity, the most notable trend is in respect of Pacific. In 1987 the Pacific Islands population had the highest employment rate of any of the measured ethnic groups. Two decades later their employment rate is lower than that of Māori and Pākehā. 
Table 1: Employment rates, 1987 and 2008 (\%)

\begin{tabular}{l|r|r}
\hline & Sept $\mathbf{1 9 8 7}$ & Sept 2008* \\
\hline Total & 63.8 & 65.8 \\
\hline Males & 75.6 & 71.9 \\
\hline Females & 52.7 & 60.1 \\
\hline Pākehā & 64.1 & 67.5 \\
\hline Māori & 58.6 & 62.5 \\
\hline Pacific Islands & 66.2 & 59.6 \\
\hline
\end{tabular}

Source: Household Labour Force Survey. $* 2008$ ethnicity data are for June.

New Zealand has also performed well in respect of unemployment over the last six years: by March 2008 our aggregate unemployment rate, $3.6 \%$, was among the lowest in the OECD. This had risen slightly to $4.2 \%$ by September 2008. While the aggregate rate is low, for some groups rates are still significant. In particular, even in a very tight labour market, unemployment among 15-24 year olds remains at over $10 \%$. Using June 2008 data, ${ }^{3}$ the Māori rate was $7.7 \%$ and the Pacifica rate was $6.3 \%$, compared with a rate among Pākehā of 2.6\%. One worrying feature of the Māori unemployment rate is that throughout the last 21 years of Household Labour Force Survey data, the Māori unemployment rate has consistently been between $2^{1 / 4}$ and $2 \frac{1}{2}$ times the aggregate rate, irrespective of labour market conditions. If this relationship continues to hold, an increase in unemployment to $10 \%$ could see a quarter of the Māori labour force unemployed.

Table 2: Unemployment rates, 1987, 1991 and 2008 (\%)

\begin{tabular}{|l|l|l|l|}
\hline & Sept 1987 & Sept 1991 & Sept 2008* \\
\hline Total & 4.1 & 10.9 & 4.2 \\
\hline Male & 3.7 & 11.6 & 4.2 \\
\hline Female & 4.7 & 10.1 & 4.1 \\
\hline $15-24$ yrs & 7.8 & 17.8 & 10.2 \\
\hline Pākehā & 3.3 & 7.6 & 2.6 \\
\hline Māori & 10.8 & 24.1 & 7.7 \\
\hline Pacific Islands & 6.6 & 26.9 & 6.3 \\
\hline
\end{tabular}

Source: Household Labour Force Survey. $* 2008$ ethnicity data are for June.

A unique labour market issue that is potentially significant for the current recession is the very high number of temporary workers currently employed in New Zealand. Immigration Service data show that the number of people holding work permits currently in New Zealand has risen from approximately 30,000 in 2001 to 135,000 in June 2008. The great majority of these workers have 1-3-year permits, and many have had their permits renewed at least once. Only about 5,000 or so are short-term seasonal workers. In principle, many of these workers should return home when their permits expire if an easing labour market means that there are now New Zealanders available to fill the jobs. In practice this is likely to depend to a significant extent on whether their employer wants to retain them. A further complication in respect of this group is that it is unclear how many are counted in the Household Labour Force Survey. The survey is only administered to those who describe themselves as 'usually resident in New Zealand', and there is no information on what proportion of work permit holders regard themselves this way.

\section{Benefit numbers}

One of the starkest differences between the starting point for this recession and that of the late 1980s-early 1990s is the situation regarding beneficiaries. In September 2008 there were 270,000 recipients of the four main benefits unemployment, domestic purposes, invalids and sickness (8.4\% of the working age population). This compares with 167,000 in 1987 ( $6.5 \%$ of the working age population). These figures relate to the principal benefit recipient and do not include spouses and other family members. As at March 2008 approximately 199,000 children were also living in families dependent on these benefits. ${ }^{4}$

The trend in benefit numbers is shown in Figure 1. As can be seen, unemployment benefit numbers have fallen sharply since 1999, reflecting the strong demand for labour, the effects of policy initiatives and Work and Income's effective case management of job seekers. At the same time, the advantages of rapid employment growth were not widely shared by sole parents on the domestic purposes benefit, whose numbers fell by only about 17,000, from a peak of about 113,000 to 96,000 in September 2008. This is likely to reflect the difficulties sole parents have in accessing affordable childcare and out-of-school care that fits with employment

\section{Figure 1: Benefit numbers by main benefit type, 1987-2008}

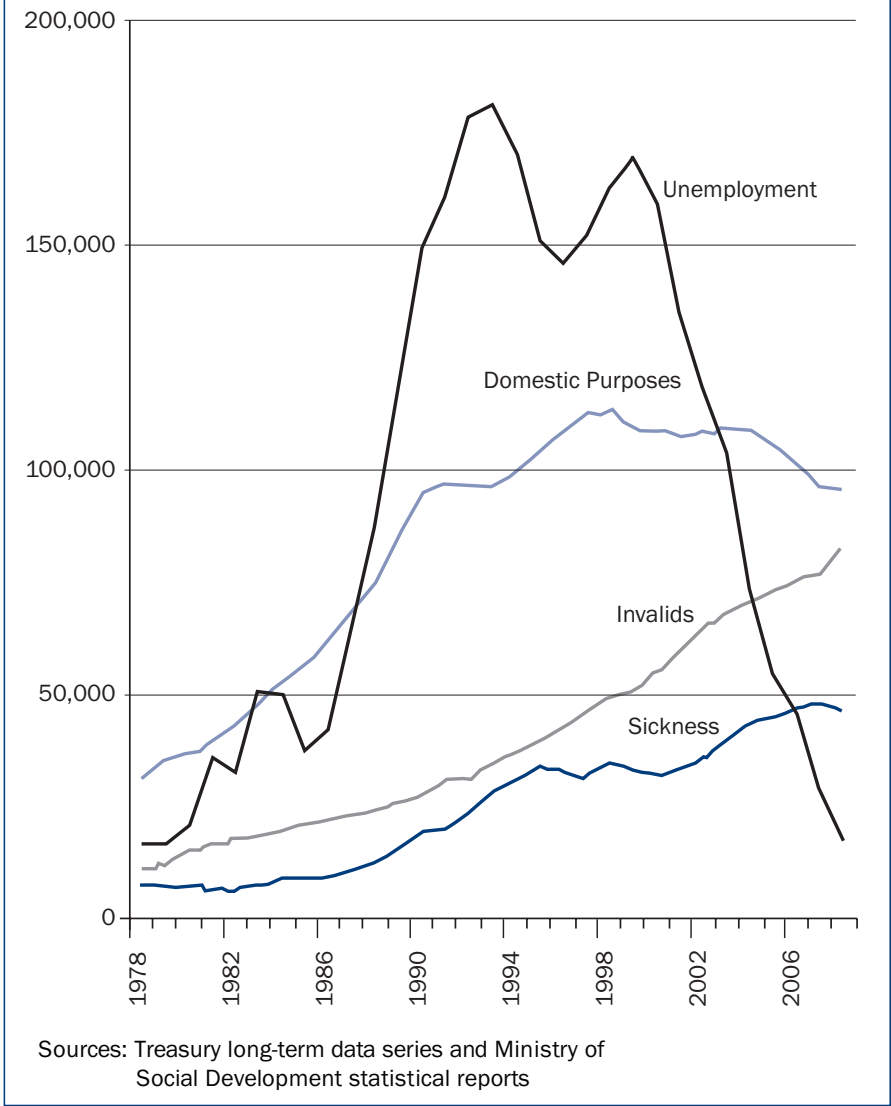


opportunities, and suggests that the in work tax credit has had only a weak impact in making paid work a practicable option for sole parents.

Also of concern is the continuing rise in invalids benefit numbers, which appear to be completely unaffected by the economic cycle. Invalids benefit numbers have risen $350 \%$, from 23,000 in 1987 to 83,000 now. Similarly, sickness beneficiary numbers have increased over the same period, from 11,000 to 46,000 . It is possible that in recent years some of this increase is attributable to people transferring from unemployment to the sickness benefit.

\section{The value of social assistance}

Exacerbating concerns about benefit numbers is the fact that the real value of most benefit incomes is now significantly lower than in the 1980s. Figure 2 plots the real value of the core benefit entitlement plus family assistance ${ }^{5}$ from 1973 to 2007 for a sole-parent and a two-parent family with two children. It shows the large fall in the 1989-91 period due to non-indexation and the 1991 benefit cuts, and the increase in assistance from 2005 due to the Working for Families initiatives. Notwithstanding those recent increases, the real value of assistance for beneficiaries with children is still well below what it was in the late 1980 s.

These data do not take into account the entire social assistance package available to beneficiaries; in particular, they do not include housing assistance, to which many beneficiaries are entitled, or third-tier assistance. However, a recent Ministry of Social Development report (Ministry of

\section{Figure 2: The real value of benefits plus family assistance, 1973-2008}

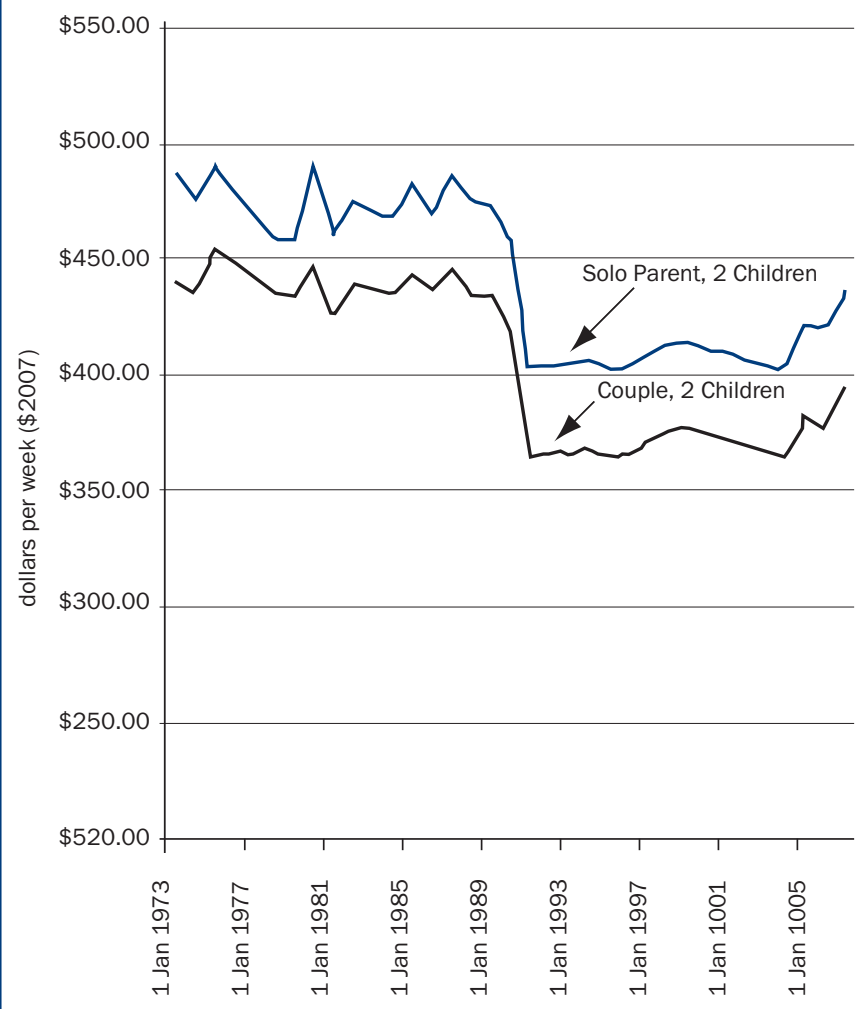

Source: Fletcher and Dwyer, 2008
Social Development, 2007) showed that in 2006 beneficiaries with children living in accommodation supplement areas 2 and 3 (i.e., most cities and towns in New Zealand) who had no other earnings had, on average, equivalised disposable incomes after housing costs and housing assistance of between 30 and $35 \%$ of the median. ${ }^{6}$

\section{Child poverty}

On both absolute and relative measures, child poverty rose steeply in the recession of the late $80 \mathrm{~s}-$-early 90 s. Following this, child poverty rates have trended downwards but, after housing costs, remain higher now than they were prior to 1988. During the growth phase child poverty became more concentrated on children living in (i) households with no adult in work, and (ii) sole-parent households, both of which groups still have child poverty rates (using the $60 \%$ of median constant value absolute poverty measure) of approximately $50 \%$. After housing costs, the number of children in poverty in 2006/07 was between 130,000 (12\%) and 230,000 (23\%), depending on which of the four measures represented in Figure 3 is used.

The extent to which New Zealand's social assistance system relies on the labour market to keep children out of poverty is illustrated in Figure 4, which plots absolute child poverty against non-employment. The trend in child poverty follows non-employment closely, with a lag of about 18-24 months. While it is important not to read too much into a simple graphical representation like this, it is notable that there appears to have been only a relatively weak response

Figure 3: Child poverty rates, after housing costs, 1982-2006/7

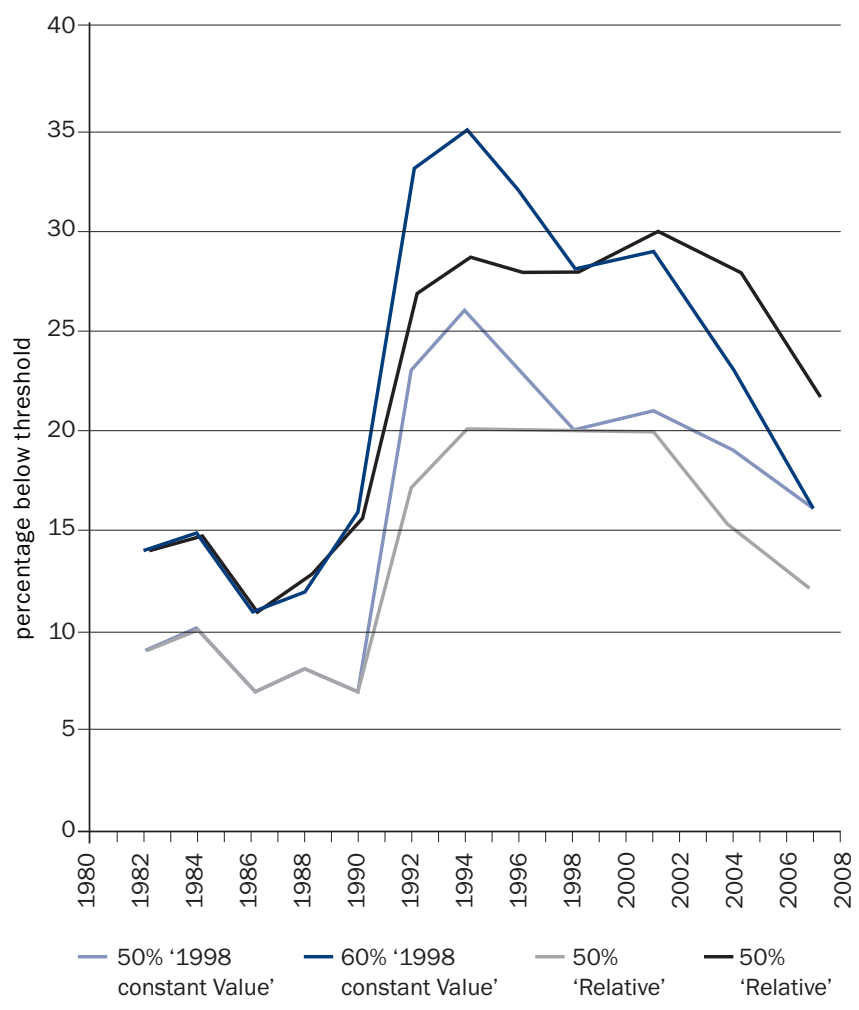

Source: Fletcher and Dwyer, 2008, based on data from Perry, 2008 
to the big fall in non-employment in the last three years, presumably reflecting the relatively high number of soleparent families still reliant on benefits.

Figure 4 is, of course, a matter of significant concern for the future. Unless we do better than in the past at supporting those dependent on benefits, the forecast rise in unemployment and decline in labour market participation will flow directly on to higher child poverty rates. There is now strong evidence of the long-lasting individual, social and economic costs associated with child poverty, especially if experienced by young children. ${ }^{7}$

\section{Household overcrowding and housing affordability}

We do not have data allowing comparisons of household overcrowding now and 20 years ago. However, 2006 data reported in The Social Report 2008 (Ministry of Social Development, 2008) show $10 \%$ of the total population and $17 \%$ of children under the age of ten living in overcrowded accommodation, based on the Canadian overcrowding index. Overcrowding is much more common among the Pacifica population (43\%) and Māori (23\%).

With respect to affordability, almost a third of children and adults under the age of 45 live in households which spend in excess of $30 \%$ of their disposable income on housing. The proportion of those in the lowest income quintile who spend this much or more on housing has doubled since 1988.

\section{Income inequality}

Finally, another big difference between the present situation and that pertaining at the end of the 1980s is that we are

Figure 4: Non-employment and child poverty, 1986-2008

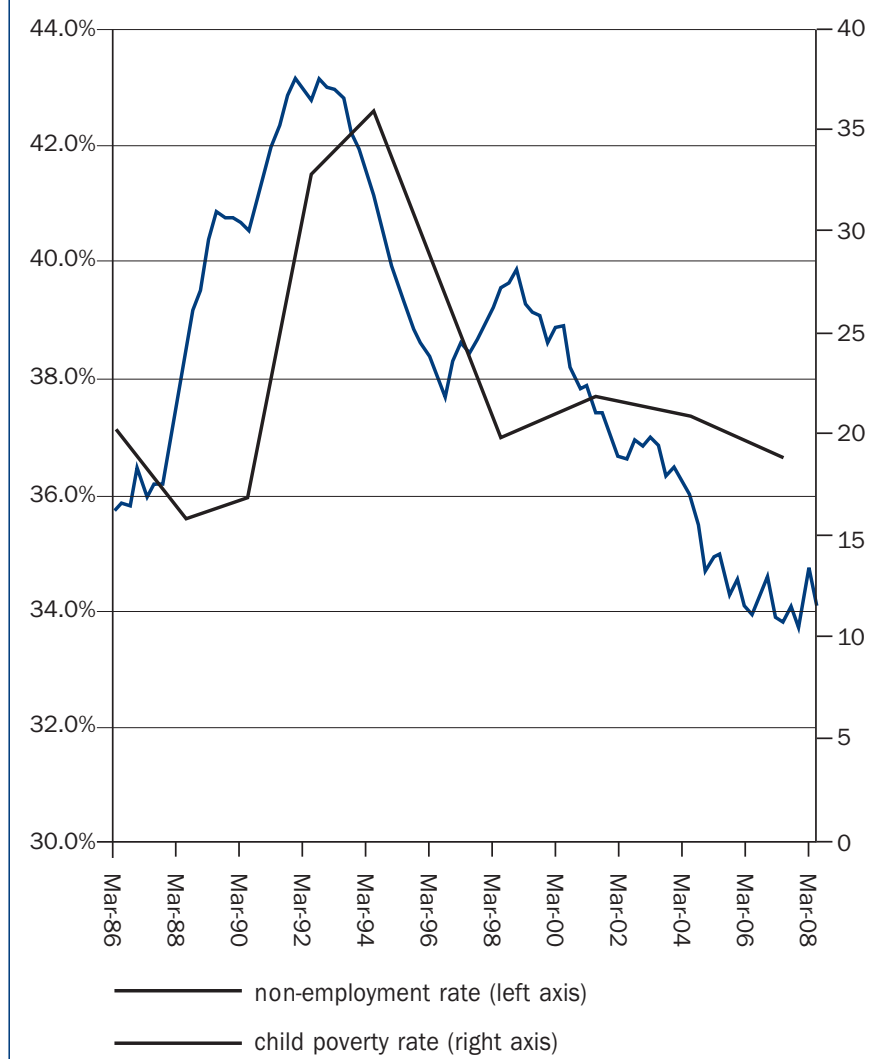

Sources: Household Labour Force Survey and Perry, 2008 entering this recession with a much higher level of income inequality than was the case then (see Figure 5). Income inequality rose more sharply in New Zealand than in any other OECD country over the period from the late 1980s to the late 1990s and remains much higher despite a slight fall in the most recent data.

It is not clear what will happen to income inequality in the next few years. It is possible that the trend will be quite different than in the late 1980s-early 1990s because of differences in the pattern of job losses and earnings trends. One possibility is that the Gini co-efficient measure, which takes into account changes in income across the whole income distribution, will remain fairly flat, whilst the ratio of the 80th percentile to the 20th percentile worsens, reflecting the impact of the recession on the less well-off compared to those in the top quintile.

\section{Social policy for the recession}

In social outcome terms the comparison between now and the beginning of the recession of 20 years ago is mixed. On the one hand, the aggregate employment rate and labour force participation is higher and the unemployment rate is similar to 1988 . On the other hand, though, many of the key indicators of social well-being are significantly worse now compared to then. In particular, beneficiary numbers are much higher and beneficiary incomes significantly lower. Child poverty rates, though lower than in the mid-1990s, are still higher after housing costs than in the 1980s, and income

Figure 5: Income inequality, 1982-2007

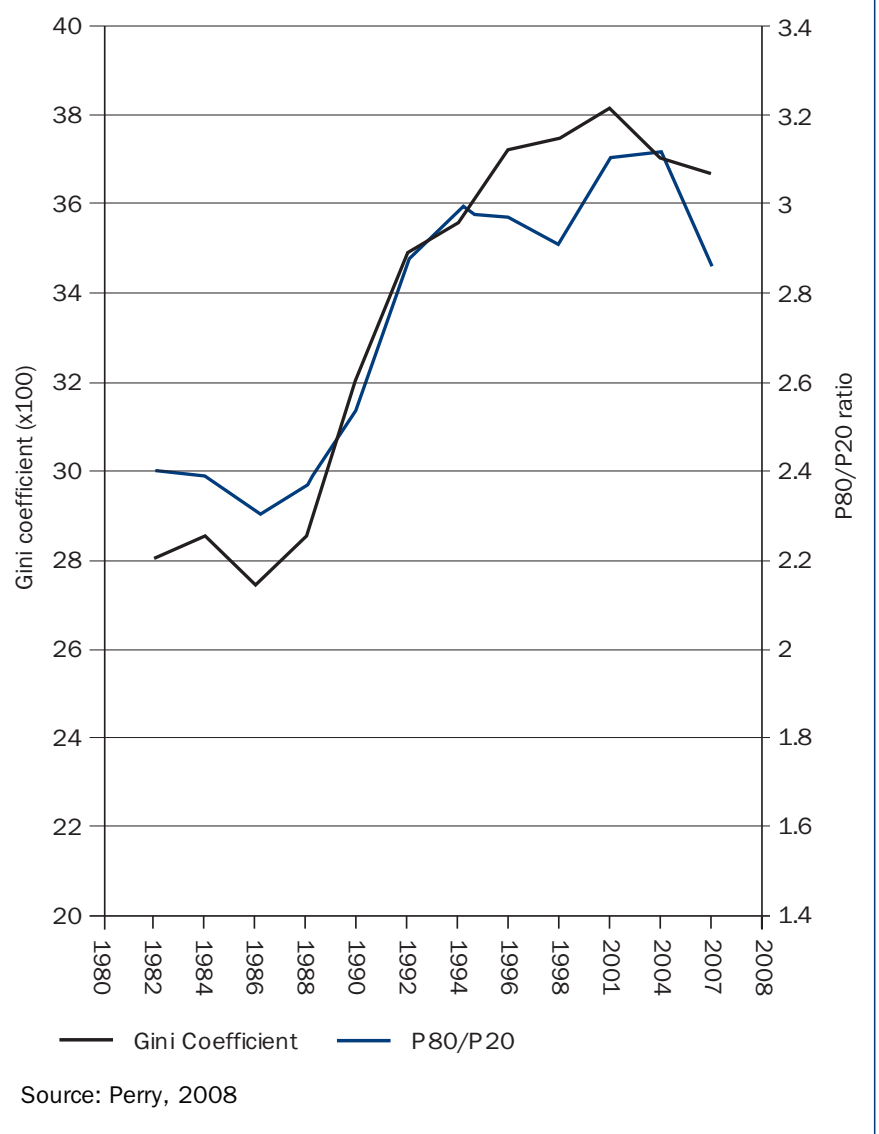


inequality is much greater than it was 20 years ago.

The second part of this article draws on the experiences of the late $1980 \mathrm{~s}^{-}$-early 1990 s to suggest some principles and priorities that should guide social policy in the recession, and then very briefly discusses three key policy areas employment policies, education and training, and social assistance and family tax credits.

\section{The importance of focusing on distributional impacts}

The 'severity' and 'duration' of a recession are both averages. For some people there will be no recession at all. For others, income losses will be large and will last long after the recession is statistically over. In the last major recession, certain groups experienced long and substantial hardship.

These groups can be identified by industry or occupation, ethnicity, education level, or in some cases the community or town they lived in. The situation then was exacerbated by policy settings based on a belief that labour markets would adjust more rapidly than they did and that aggregate losses would be minimised by allowing that adjustment to occur without too much intervention.

One likely difference between this recession and that of 1988-93 is that then the downturn was associated with a process of economic restructuring that was a strong factor in determining the distributional impacts, particularly in respect of employment losses. This time, despite the global financial crisis and the probable need to restructure or re-regulate global financial practices, it is less likely to result in much restructuring of the New Zealand economy, in the sense of significant shifts in output or employment shares. This suggests that it is even more important to maintain, as far as possible, the existing human capital and skills of the workforce and to avoid the extremely high rates of unemployment and poverty and loss of infrastructure that occurred in many New Zealand towns in the late $80 \mathrm{~s}-$-early $90 \mathrm{~s}$.

\section{Prioritise the least well-off and children, where the long-term} social and economic costs are greatest

In seeking to ameliorate the negative impacts of the recession, policy makers must aim for some balance between cushioning the effects on those who experience the biggest shocks to their income and/or wealth, and protecting those who are least well-off. There is a risk that too much of the former results in middle-class capture of the available assistance. Quite aside from arguments of equity and social justice, the experience of the 1990s and since is strong evidence of the long-term consequences of not ensuring adequate support for the poorest communities and for children in low-income households.

Be aware of the long-term impacts of policy changes on the social policy framework

Some policies introduced to counter the effects of the recession are reversible - they can either be easily ended when no longer needed, or automatically phased out when circumstances improve. As a result they have no lasting effect on the structure or mix of social policies and welfare provisions. Others do, however, have long-term implications for the overall social policy framework. The 1991 benefit cuts, for example, have never been reversed, despite the evidence of income inadequacy among beneficiaries.

Another example of this issue is the 'Restart' package to assist those who are made redundant that was announced by the government on 15 December 2008. Pre-election versions of this package proposed by both major parties could potentially have introduced into the New Zealand welfare system elements of a two-tier social insurance/safety net

\section{The 'severity' and 'duration' of a recession are both averages. For some people there will be no recession at all. For others, income losses will be large and will last long after the recession is statistically over.} . 
jobs should be supported. Clearly, demand-side measures can help; as will government infrastructure projects (which should include social infrastructure such as state house building, etc).

In terms of employment programmes for the unemployed, the evaluation evidence from the 1990s showed that wage subsidies for full-time/permanent employment (eg, Job Plus) worked relatively well, while 'work-readiness' and workfor-dole schemes such as Community Taskforce were not effective in increasing people's chance of getting back into employment. Temporary full-time, full-wage, project-based programmes such as Taskforce Green can be beneficial, depending on the project and the quality of administration. One advantage we have now compared with 20 years ago is the considerable improvement in Work and Income's case management processes and in its links with employers and communities at the local level.

many occupations. In addition to the benefits to those taking up apprenticeships, such a policy would ensure that a good supply of skilled workers is available when demand picks up.

There is scope, too, to expand access to the training incentive allowance which helps beneficiaries with tertiary education, including university study.

\section{Benefits and tax credits}

Benefit rates are lower than they were in the 1980s and entitlements are below what is necessary for many beneficiaries to avoid poverty and significant hardship. Notwithstanding worsening government accounts, there is a strong case for raising benefit levels to ensure the recession does not result in the same rapid increase in child and adult poverty that New Zealand experienced in the 1990s. In that period, the longterm effects on the individuals affected and on wider social and economic outcomes were clear.

As well as increasing core rates of benefit, it would help to adopt an indexing regime similar to that used for New Zealand Superannuation - annual CPI adjustments within a band linked to average wages. The effect of this would be to constrain benefit rate increases if the recession results in falling real wages, while at the same time ensuring that over the long term benefits maintain relativity with wages.

Accommodation supplement (AS) maxima also need increasing - and could perhaps be increased ahead of benefit rates as an interim,

The issue of targeting of employment assistance will need further analysis. During the 1980s and 1990s, active labour market assistance was targeted mostly at the longterm unemployed (defined in most cases as 26 weeks-plus duration on the job seeker register). The relationship between inflows, outflows and duration means that in the early stages at least, when unemployment numbers will be dominated by new enrolments, a focus on long duration makes little sense. Even later, as the proportion of long-term unemployed grows, it may be better to target other characteristics. Males over 40 years old, for example, are at a higher risk of longterm unemployment than are young people, who tend to experience more, shorter spells out of work. Given what we know of the impact of poverty on children, it may also make sense to focus on those with dependent children, and especially young children.

\section{Training and education programmes}

Past experience shows that short-term training courses, such as ACGESS, Māori ACCESS and the Training Opportunity Programme (TOP), are not very effective either in raising participants' skill levels or in enhancing their subsequent employment chances. It would be better to put considerable money into subsidising longer-term education and training opportunities of the sort that lead to meaningful skill acquisition and recognised qualifications. Even in a downturn in demand for many trades and similar services, there will be opportunities to subsidise modern apprenticeship places in more targeted measure. The proportion of AS recipients who have reached the maximum has been increasing steadily and is now over 30\%. The government's 'Replace' assistance to those made redundant is a limited step in this direction, albeit available to only a very narrow group of AS recipients and for only a short period of time.

Weak labour demand accentuates the case for revising aspects of the Working for Families package. The package - which undoubtedly provided substantial, much-needed assistance for many families - was designed to take advantage of a strong labour market by encouraging beneficiaries with children to move off benefits and into paid work. In circumstances of falling employment, components of the package such as the in-work tax credit are unlikely to have any effect in reducing unemployment. A further difficulty with the in-work tax credit is that it is not well targeted as a 'make work pay' measure, since most of the expenditure goes to those higher up the income distribution, for whom the gap between wages and benefits is not relevant.

In a situation of falling employment and rising benefit dependence it would be preferable to remove the in-work tax credit and transfer the expenditure to an increase in the core family tax credit. At the same time it would be possible to simplify the current five family tax credit rates (which are largely historical accidents) in such a way as to give relatively more of the additional expenditure to families with young children. Poverty in the early years is known to be most likely 
to have lasting detrimental effects, and, in addition, it is when children are young that families tend to have the greatest financial difficulties.

\section{Conclusions}

New Zealand is entering what appears likely to be a serious and protracted recession with a mixed set of social indicators. While employment is high and unemployment low, the number of people dependent on benefits is considerably higher than at the beginning of the last significant downturn, and the incomes of beneficiaries are lower. Income inequality is also much higher than it was 20 years ago.

The experience of the 1990s suggests that, quite apart from arguments of social justice, a deliberate policy focus on expenditures to minimise the impacts of the recession on the most vulnerable, and especially on children, will significantly improve New Zealand's social and economic indicators after the recession is over. This article touches on only a small number of the range of policy initiatives needed to achieve this.

\footnotetext{
1 An earlier version of this paper was presented at the Institute of Policy Studies symposium 'New Zealand Economic and Social Policy in the Face of the Global Crisis', held on 22 November 2008.

2 Technically that recession was over a much shorter period, but the period of low employment growth and high unemployment lasted that long.

3 Consistent September quarter data are not available as Statistics New Zealand has changed its ethnicity classifications from a hierarchical method to a multiple-response method. Backdated data using the new system are expected to be available shortly.

4 I do not have September 2008 data or a comparable figure for the 1980s.

5 Family benefit, family care, family support and family tax credit.

6 The minority with some earnings in addition to their benefit had incomes averaging about $43 \%$ of the median.

7 See, for example, Hirsh, 2006 and Poulton et al., 2002.
}

\section{References}

Fletcher, M. and M. Dwyer (2008) A Fair Go for All Children: actions to address child poverty in New Zealand, Wellington: Office of the Children's Commission

Hirsch, D. (2006) What Will it Take to End Child Poverty? Firing on all cylinders, York: Joseph Rowntree Foundation
Ministry of Social Development (2007) Pockets of Significant Hardship and Poverty, Wellington: Ministry of Social Development Ministry of Social Development (2008) The Social Report 2008, Wellington: Ministry of Social Development

Perry, B. (2008) Household Incomes in New

Zealand: trends in indicators of inequality and hardship 1982-2007, Wellington: Ministry of Social Development

Poulton, R., A. Caspi, B.J. Milne, W.M. Thomson, A. Taylor, M.R. Sears and T.E. Moffitt (2002) 'Association between children's experience of socioeconomic disadvantage and adult health: a life course study', Lancet, 360, pp.1640-5

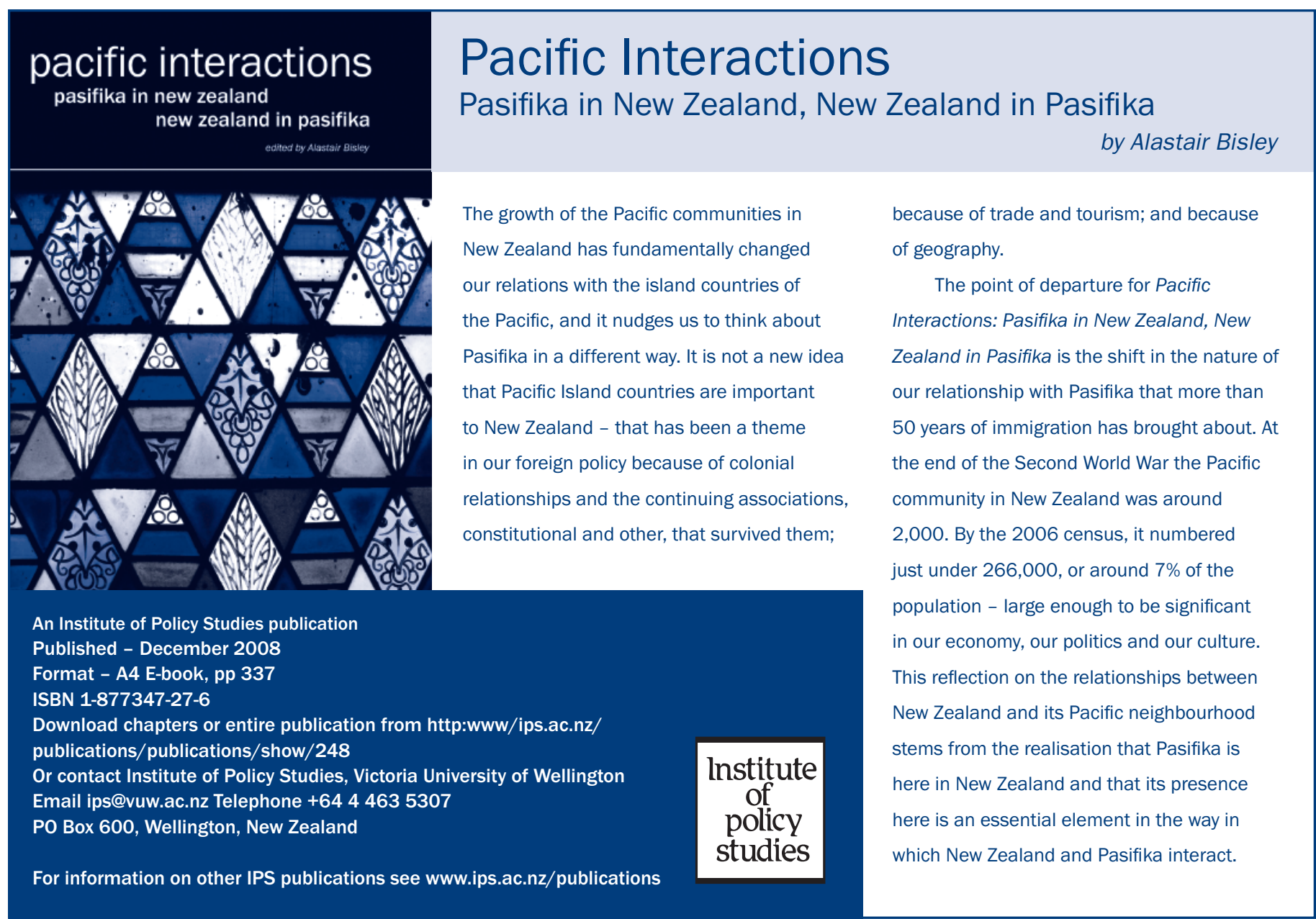

